\title{
Epidemiological characteristics of scrub typhus on the Jeju Island
}

\author{
Jong-Myon Bae \\ Department of Preventive Medicine, Jeju National University Scool of Medicine, Jeju, Korea
}

Dear Editor,

Lee [1] reported the epidemiological characteristics of scrub typhus cases that occurred from 2011 through 2016 on Jeju Island, and presented a hypothesis that citrus farming is the main risk factor for the infectious disease. However, I found several methodological and logical problems in the process by which the hypothesis was established. In this Letter to the Editor, I summarize the problems into the following 5 categories.

First, the author stated that to examine the incidence of scrub typhus on Jeju Island by year and by region, "the total population of Jeju Island and the population by region were based on the average population from 2011 to 2015 from the National Statistics Office data in Korea." Based on the statement, it is inferred that the incidence rates presented in Tables 1 and 2, and Figure 1 are crude incidence rates (CIR), and not adjusted for age and sex. If that is CIR, age-adjusted and sex-adjusted incidence rates for comparability should be estimated and the analysis repeated [2]. It is also recommended to compute the $95 \%$ confidence intervals (CIs).

Second, the author stated in the Data Analysis section that "The Mann-Whitney U-test was used as a non-parametric measure for comparing 2 independent groups" and showed three p-values in Table 2. He interpreted the first $\mathrm{p}$-value, $\mathrm{p}=0.006$, in the Results by stating that "there was a statistically significant difference in the incidence of scrub typhus per 100,000 persons between Jeju-si and Seogwipo-si among the urbanized 'dong' area regions." The other two p-values were also similarly interpreted. However, Table 2 lists incidence rates in Jeju and Seogwipo cities across 6 years as the dependent variables. In other words, it seems that the com-

\section{Correspondence: Jong-Myon Bae}

Department of Preventive Medicine, Jeju National University School of Medicine, 102 Jejudaehak-ro, Jeju 63243, Korea

E-mail:jmbae@jejunu.ac.kr

This article is available from: http://e-epih.org/

(C) This is an open-access article distributed under the terms of the Creative Commons Attribution License (http://creativecommons.org/licenses/by/4.0/) which permits unrestricted use, distribution, and reproduction in any medium, provided the original work is properly cited.

(C) 2017, Korean Society of Epidemiology parison of 2 groups were performed, as stated, but if there were 2 dependent variables by 6 periods respectively, the choice of MannWhitney U-test was inappropriate [3]. Additionally, it is recommended to conduct a test for trends.

Third, in the Data Analysis section, the author stated that the Pearson's chi-square test was performed "to determine if there was a difference between discontinuous variables consisting of an rby-c table." And, in interpreting the results of the risk factor analysis, he stated that "there was a significant difference in the distribution of outdoor exposures between public health centers." However, the row in Table 3 included not only the histories of 3 outdoor exposures but also "others," making it difficult to properly interpret the p-value. If the author conducted "risk factor analysis," it is recommended to re-categorize outdoor exposures and present prevalence odds ratios as well as their CIs [4].

Fourth, to establish the hypothesis that working at a citrus farm is a risk factor, the author stated in the Discussion that "the unique point was that the infection rate was the highest while working in orchards, and the main related work was mandarin orange farming." Additionally, the author reported that " $78.8 \%$ of Agricultural Cooperative mandarin shipment on Jeju Island were reported to have been shipped from Seogwipo-si 'dong' area and Namwoneup in Seogwipo East region." However, the data shown in Table 3 are the number of reported incident cases (i.e., descriptive epidemiology). To make such inference as above, 'the difference in incidence level between citrus and non-citrus farming' should be presented. Considering that unlike other regions, farming in Jeju Island is mostly for citrus, the author's inference lacks evidence, unless the risk of scrub typhus is examined by the type of fruit farming. Just based on the findings in the study, it would be a stretch to argue that citrus farming poses more danger than other types of fruit farming on Jeju Island.

Fifth, the author stated in the Discussion that the high incidence in 2016 has to do with higher levels of mean temperature and dryness in August. However, Park et al. [5] described that it was difficult to identify the relationship between the density of mites and number of reported cases of scrub typhus (NRC) in 2016 even though higher temperature of August as the breeding season of 


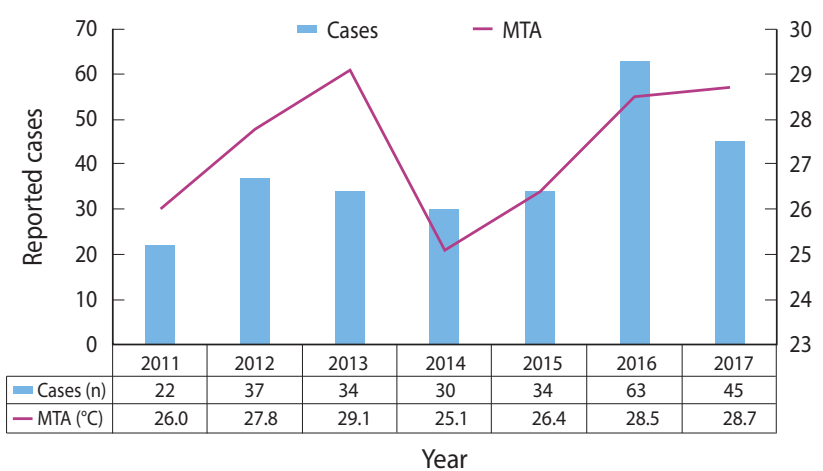

Figure 1. The reported cases of scrub typhus and mean temperature of August (MTA) in Jeju-si (Spearman's rho $=0.65, p=0.12$; Kendall's tau- $a=0.48, p=0.17$ ).

mites is causing the higher density of mites. Thus, it is necessary to review the mean temperatures of August (MTA) from 2011 to 2016 and present relevant evidence. When the weather information provided by Korea Meterological Administration showed that MTA in 2013 was higher than that in 2016 [6]. A correlation analysis between MTA and NRC provided by Korea Centers for Diseases Control and Prevention [7] in 2011-2017 was conducted by Jeju-si and Seogwipo-si. Spearman's rho and Kendall's tau-a in Jeju-si were $0.65(\mathrm{p}=0.12)$ and $0.48(\mathrm{p}=0.17)$, respectively (Figure 1). Same coefficiencies in Seogwipo-si were $0.14(\mathrm{p}=0.76)$ and $0.24(\mathrm{p}=0.55)$, respectively (Figure 2$)$. Based on these results, it is important to distinguish density of mites from the proportion of mites infected by Oritenta tustusgamushi.

If the aforementioned five issues are not addressed with valid analysis and reasoning, it is difficult to accept the author's hypothesis from methodological and logical points of view.

\section{ACKNOWLEDGEMENTS}

Thanks to Yu Jeong Han as a member of Jeju Center for Infection Control for extracting and arranging the information of the mean temperature of August and the number of cases reported as scrub typhus in Jeju-si and Seogwipo-si.

\section{CONFLICT OF INTEREST}

The author has no conflicts of interest to declare for this study.

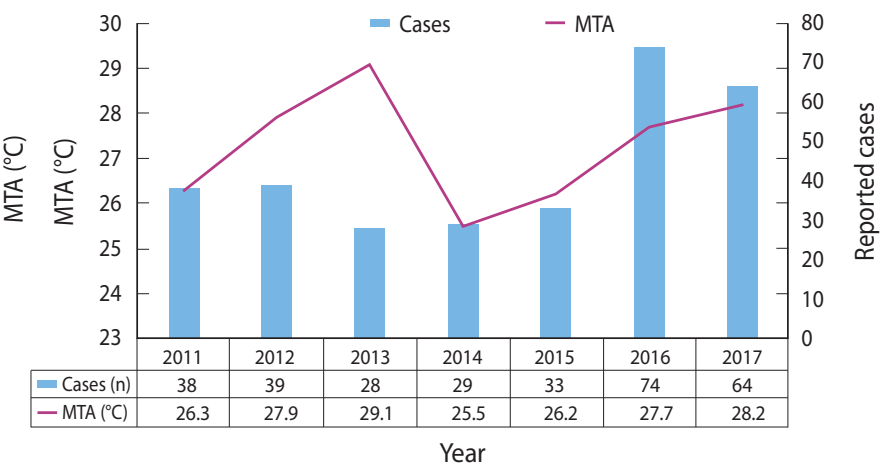

Figure 2. The reported cases of scrub typhus and mean temperature of August (MTA) in Seogwipo-si (Spearman's rho $=0.14, p=0.76$; Kendall's tau- $a=0.24, p=0.55$ ).

\section{SUPPLEMENTARY MATERIAL}

Supplementary material (Korean version) is available at http:// www.e-epih.org/.

\section{ORCID}

Jong-Myon Bae: http://orcid.org/0000-0003-3080-7852

\section{REFERENCES}

1. Lee SU. Epidemiologic characteristics of scrub typhus on Jeju Island. Epidemiol Health 2017;39:e2017039.

2. Tiwari RC, Clegg LX, Zou Z. Efficient interval estimation for ageadjusted cancer rates. Stat Methods Med Res 2006;15:547-569.

3. Nam CM, Chung SY. Statistical methods for medical studies. J Korean Med Assoc 2012;55:573-581 (Korean).

4. Thompson ML, Myers JE, Kriebel D. Prevalence odds ratio or prevalence ratio in the analysis of cross sectional data: what is to be done? Occup Environ Med 1998;55:272-277.

5. Park WI, Roh JY, Cho SH. Surveillance of chigger mites as the vector of scrub typhus, 2016. Public Health Wkly Rep 2017;10:10581061 (Korean).

6. Korea Meteorological Administration. Weather information [cited 2017 Dec 31]. Available from: https://data.kma.go.kr/data/grnd/ selectAsosRltmList.do?pgmNo = 36 (Korean).

7. Korea Centers for Diseases Control and Prevention. Disease web statistics system [cited 2017 Dec 31]. Available from: https://is. cdc.go.kr/dstat/jsp/stat/stat0002.jsp (Korean). 


\title{
Epidemiologic characteristics of scrub typhus on Jeju Island
}

\author{
Sung Uk Lee \\ Jeju Special Self-Governing Provincial Office, Jeju, Korea
}

In the article [1], patient and disease characteristics were examined in 446 patients with scrub typhus that occurred in the Jeju area between 2011 and 2016. The most commonly observed history of exposure was fruit farming $(n=155,35 \%$ of the entire sample), and $91 \%$ of those with an exposure to fruit farming worked to harvest citrus fruits. That is, a "phenomenon" was observed in which citrus farming is likely to be an important infection route of scrub typhus on the Jeju Island. It is stressed, however, that the study was not conducted with an aim to establish and prove a certain hypothesis with statistical techniques. Rather, the focus of the study was on quantifying the surveyed information to derive facts themselves. To "hypothesize" about the "phenomenon" observed in the present study, additional research should be conducted.

Below are responses to the problems additionally raised by the reader.

First, it is problematic since the age-adjusted and sex-adjusted incidences including 95\% confidence intervals were not used. Figure 1 and Table 2 in the original manuscript [1] have been newly generated after calculating the age-adjusted incidence using the data from Statistics Korea in January 2016 (Table 1 and Figure 1) [2]. Please note that Figure 1 was obtained based on mean values of 6 years from 2011 to 2016 . In comparison to the crude incidence in the original manuscript [1], there were clear number changes (mostly increases) in 'eub' and 'myeon' regions than 'dong' regions. Thus, we could observe the same trend as that in the original manuscript [1] by comparing both incidence rates by region and between regions.

The second is regarding the reader's comment on the use of MannWhitney U-test in statistical analysis. The author of the present

\section{Correspondence: Sung Uk Lee}

Jeju Special Self-Governing Provincial Office, 6 Munyeon-ro, Jeju 63122, Korea

E-mail: sulee86@korea.kr

This article is available from: http://e-epih.org/

(c) This is an open-access article distributed under the terms of the Creative Commons Attribution License (http://creativecommons.org/licenses/by/4.0/), which permits unrestricted use, distribution, and reproduction in any medium, provided the original work is properly cited.

(C) 2017, Korean Society of Epidemiology study aimed to examine whether the annual incidence rates per 100,000 population were significantly different between two independent areas, A and B, during the 6 years. Using Mann-Whitney U-test in such a case is also recommended in the reference cited by the reader. Because what the author wanted to find out was whether or not there were a regional difference between A and B, trend analysis was irrelevant in the present study.

The third is regarding the reader's comment on Table 3 . This table shows the distributions of cases by main cause of scrub typhus in each region. The table was intended to demonstrate that "the distribution was different across 6 regions," rather than to show "prevalence odds ratios" with respect to risk factors. As discussed in the article [1], the table was presented to suggest that the focus of scrub typhus prevention projects should differ for each public health center, because the main causes were different among the regions. Also, the study found that the number of infected patients increased following citrus farming but unfortunately, it is not a study intended to prove that citrus farming is more risky than other types of farming.

Fourth, the relevance of high incidence in 2016 to the mean temperature and dryness in August was not an argument made by the author. The author simply cited the inference made by the Korea Centers for Disease Control and Prevention [3].

With these, the author expresses his thanks for the interest in the present study and the work of the reader and closes this reply.

\section{CONFLICT OF INTEREST}

The author has no conflicts of interest to declare for this study.

\section{SUPPLEMENTARY MATERIAL}

Supplementary material (Korean version) is available at http:// www.e-epih.org.

\section{ORCID}

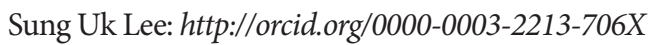


Table 1. Age-adjusted incidence rate ${ }^{1}$ of scrub typhus per 100,000 by region in Jeju province

\begin{tabular}{|c|c|c|c|c|c|c|c|c|c|c|c|c|c|c|}
\hline & \multirow[b]{2}{*}{ Regions } & \multicolumn{2}{|c|}{2011} & \multicolumn{2}{|c|}{2012} & \multicolumn{2}{|c|}{2013} & \multicolumn{2}{|c|}{2014} & \multicolumn{2}{|c|}{2015} & \multicolumn{2}{|c|}{2016} & \multirow[b]{2}{*}{$p$-value ${ }^{2}$} \\
\hline & & $\begin{array}{l}\text { Case } \\
\text { (n) }\end{array}$ & $\begin{array}{l}\text { Inci- } \\
\text { dence }\end{array}$ & $\begin{array}{c}\text { Case } \\
\text { (n) }\end{array}$ & $\begin{array}{l}\text { Inci- } \\
\text { dence }\end{array}$ & $\begin{array}{l}\text { Case } \\
\text { (n) }\end{array}$ & $\begin{array}{l}\text { Inci- } \\
\text { dence }\end{array}$ & $\begin{array}{c}\text { Case } \\
\text { (n) }\end{array}$ & $\begin{array}{l}\text { Inci- } \\
\text { dence }\end{array}$ & $\begin{array}{c}\text { Case } \\
\text { (n) }\end{array}$ & $\begin{array}{l}\text { Inci- } \\
\text { dence }\end{array}$ & $\begin{array}{c}\text { Case } \\
\text { (n) }\end{array}$ & $\begin{array}{l}\text { Inci- } \\
\text { dence }\end{array}$ & \\
\hline \multirow[t]{2}{*}{ City } & Jeju-si & 9 & 0.7 & 16 & 2.0 & 13 & 1.6 & 14 & 1.9 & 6 & 0.3 & 34 & 4.0 & 0.004 \\
\hline & Seogwipo-si & 12 & 18.0 & 10 & 10.7 & 8 & 8.8 & 9 & 10.5 & 13 & 19.8 & 16 & 12.2 & \\
\hline \multirow{4}{*}{$\begin{array}{l}\text { Country- } \\
\text { side }\end{array}$} & - Jeju East & 1 & 0.7 & 7 & 28.8 & 8 & 49.4 & 4 & 10.8 & 7 & 29.6 & 10 & 25.3 & 0.20 \\
\hline & Jeju West & 10 & 28.2 & 13 & 40.9 & 8 & 20.2 & 11 & 33.8 & 18 & 80.8 & 21 & 45.9 & \\
\hline & Seogwipo East & 18 & 152.5 & 18 & 130.4 & 13 & 89.6 & 16 & 120.7 & 13 & 71.5 & 60 & 629.3 & 0.004 \\
\hline & Seogwipo West & 7 & 57.9 & 8 & 64.7 & 2 & 5.3 & 1 & 1.2 & 4 & 16.7 & 8 & 27.8 & \\
\hline
\end{tabular}

1Population distribution data by age was applied as of January 2016 for estimating age-adjusted incidence. ${ }^{2} \mathrm{p}$-value by Mann-Whitney U-test for the incidence.

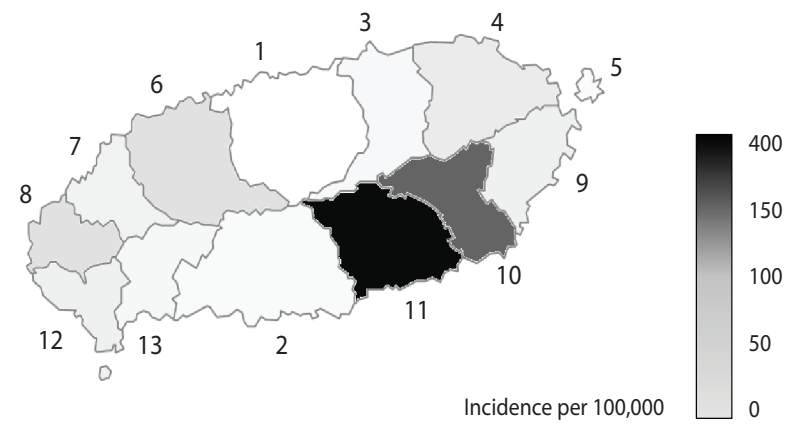

Figure 1. Average age-adjusted incidence rate per 100,000 of scrub typhus in Jeju Island, 2011-2016 (1, Jeju-si;2, Seogwipo-si; 3, Jocheoneup; 4, Gujwa-eup; 5, Udo-myeon; 6, Aewol-eup; 7, Hallim-eup; 8 , Hangyeong-myeon; 9 , Seongsan-eup;10, Pyoseon-myeon; 11, Namwon-eup; 12, Daejeong-eup; 13, Andeok-myeon).

\section{REFERENCES}

1. Lee SU. Epidemiologic characteristics of scrub typhus on Jeju Island. Epidemiol Health 2017;39:e2017039.

2. Statistics Korea. 'Demographic change in Jeju province'; 2016 [cited 2017 Dec 31]. Available from: m.kostat.go.kr/board/file_dn.jsp?aSeq $=354804$ \&ord $=1$ (Korean).

3. Korea Centers for Disease Control and Prevention. Infectious disease surveillance year book 2016; 2017 [cited 2017 Aug 1]. Available from: http://cdc.go.kr/CDC/info/CdcKrInfo0302.jsp?menuIds = HOME001-MNU1132-MNU1138-MNU0038\&fid = 32\&q_ type $=\&$ q_value $=\&$ cid $=75290 \&$ pageNum $=($ Korean $)$. 